Artigo Original

Hegemonia - Revista Eletrônica do Programa de Mestrado em Direitos Humanos, Cidadania e

Violência/Ciência Política do Centro Universitário Unieuro

ISSN: 1809-1261

UNIEURO, Brasília, número 27 (Especial), 2019, pp. 265-290.

Recebido em: 3/9/2018

Avaliado em: 26/10/2018

Aprovado em: 28/11/2018

\title{
NORMAS TRIBUTÁRIAS COMO INSTRUMENTO DE PRESERVAÇÃO AMBIENTAL
}

\author{
Aline Martins Ferreira ${ }^{1}$ e Cristina Melo Gonçalves ${ }^{2}$
}

Resumo: O presente artigo objetiva refletir acerca da tributação voltada à proteção do meio ambiente, em que o Estado atua por normas tributárias extrafiscais como instrumento incentivador ou indutor de condutas sustentáveis. A motivação desse estudo fundamenta-se no pressuposto de que a tributação pode desempenhar função garantidora do meio ambiente ecologicamente equilibrado e sadio, direito fundamental previsto na Constituição Federal. Por intermédio da utilização do método de pesquisa bibliográfica, chegou-se à conclusão de que o incentivo fiscal são instrumentos eficazes a não poluição, de forma que toda a coletividade se beneficia com a proteção do patrimônio ambiental.

Palavras-chave: Tributação ecológica; Direito ambiental; Extrafiscalidade; Incentivos fiscais.

Abstract: The present article aims to reflect on taxation aimed at protecting the environment, in which the State acts by extra-fiscal tax rules as an incentive instrument or inducer of sustainable conduct. The motivation of this study is based on the assumption that taxation can play a guarantor of the ecologically balanced and healthy environment, a fundamental right provided for in the Federal Constitution. Through the use of the bibliographic research method, it was concluded that the tax incentive are effective instruments to non-pollution, so that the whole community benefits from the protection of environmental patrimony.

Keywords: Ecologic taxation; environment regulation; incentive tribute.

\section{1 - INTRODUÇÃO}

O Estudo realizado neste artigo trata da relação do direito ambiental com o direito tributário, no que tange à análise das normas tributárias voltadas à proteção ambiental (extrafiscalidade), de forma que tais normas podem ser mecanismos de estímulo ou interferência na conduta socioambiental dos contribuintes, para que assim se alcance uma sustentabilidade efetiva, um meio ambiente sadio

\footnotetext{
${ }^{1}$ Bacharel em Direito pelo Centro Universitário Euro-Americano (UNIEURO/DF).

2 Doutoranda em Parcerias na Saúde pela Universidade de Brasília.
} 
Artigo Original

Hegemonia - Revista Eletrônica do Programa de Mestrado em Direitos Humanos, Cidadania e Violência/Ciência Política do Centro Universitário Unieuro

ISSN: 1809-1261

UNIEURO, Brasília, número 27 (Especial), 2019, pp. 265-290.

e ecologicamente equilibrado, como um direito fundamental a todos os cidadãos, conforme previsto na Carta Maior.

\section{2 - O SISTEMA TRIBUTÁRIO NACIONAL}

O sistema tributário implica em um conjunto de organização econômica pelo qual o Estado exerce a imposição tributária, ou seja, o poder de tributar com fim de arrecadação das finanças públicas. Assim, confirmando que o direito tributário é parte do ordenamento jurídico global, Klaus Tipke afirma, que: "a liberdade de contraposição dos valores fundamentais do direito e da justiça são elementos essenciais de um ordenamento"

Nesse prospecto, Alejandro Altamiro entende que tudo está em consonância com a Constituição. Afirma, também que, para “o direito tributário, a Constituição assume o papel principal de iluminar as diretivas fundamentais dentro das quais se desenvolve o poder de tributar (isto é, instituir tributos para se obter receitas públicas). Como consequência, os direitos e obrigações tanto do Estado como do contribuinte convergem para a Constituição"”.

Posto isso, entende-se como sistema tributário a forma que o Estado se estrutura para o exercício do poder imposto pelos diversos órgãos públicos, buscando-se assim a harmonia das relações da sociedade na arrecadação de receitas que é regulamentada na magna carta. Trata-se, então, de formas pelas quais a sociedade garante os seus próprios objetivos e executa seus projetos.

Com isso, confirmando o caráter federal do Estado Brasileiro e a posição de domínio que nele ocupa o Distrito Federal, elencou e distribuiu, cuidadosamente, as várias competências de cada uma das pessoas políticas. Assim, no Brasil não falamos em "poder tributário", mas em competência tributária por vários preceitos da Constituição, pois o Estado necessita captar recursos materiais para manter a sua estrutura.

Criar tributos é legislar, administrar e arrecadar, cujo pagamento é exigido dos cidadãos que

\footnotetext{
${ }^{3}$ TIPKE, Klaus, Apud: NETTO DE OLIVEIRA, Alexandre. Compatibilidade de um tributo ambiental com o sistema tributário nacional. Dissertação (Mestrado em Direito) - Departamento de Direito Econômico, Financeiro, e Tributário da Faculdade de Direito da Universidade de São Paulo - USP, São Paulo, 2014.

${ }^{4}$ ALTAMIRO, Alejandro, Apud NETTO DE OLIVEIRA, Alexandre. Compatibilidade de um tributo ambiental com o sistema tributário nacional. Dissertação (Mestrado em Direito) - Departamento de Direito Econômico, Financeiro, e Tributário da Faculdade de Direito da Universidade de São Paulo - USP, São Paulo, 2014.
} 
Artigo Original

Hegemonia - Revista Eletrônica do Programa de Mestrado em Direitos Humanos, Cidadania e Violência/Ciência Política do Centro Universitário Unieuro

ISSN: 1809-1261

UNIEURO, Brasília, número 27 (Especial), 2019, pp. 265-290.

estão submetidos à soberania do Fisco. Significa dizer que, quem pode tributar, da mesma forma também possui aptidão para minorar, aumentar, diminuir, parcelar e isentar, desde que se observem as diretrizes constitucionais. Não há Estado sem direito e nem Estado sem Tributo, pois em sua atividade financeira, o Estado necessita de recursos para executar a política estatal, manter sua estrutura e disponibilizar ao cidadão contribuinte os serviços que lhe competem, como provedor das necessidades coletivas.

\section{3 - A ATUAÇÃO DIRETA E INDIRETA DO ESTADO}

Ao se analisar a forma de atuação do Estado, constata-se que ele age de maneira direta e indireta com relação aos efeitos da norma tributária produzidos sobre o contribuinte. Sendo assim, as normas indutoras são como instrumentos de intervenção econômica.

Assim, busca-se com a atuação do Estado, induzir e/ou alcançar um determinado comportamento do contribuinte, desejado ou não pelo legislador. Acresce-se a isso que "as normas tributárias indutoras vincula a determinado comportamento um consequente, que poderá consistir em vantagem (estímulo) ou agravamento de natureza tributária primária, na qual se faz presente à indução ${ }^{5 \%}$.

A partir disso, por mais que um tributo seja concebido, em sua formulação, como instrumento de intervenção sobre o domínio econômico, jamais se descuidará da receita dele decorrente. Em regra o legislador tributário não precisa valer-se de um "tributo indutor" propriamente dito, para atingir suas finalidades, porém deve-se buscar o desenvolvimento e não o mero crescimento econômico fazendo com que os agentes tenham suas atividades voltadas para o crescimento também social.

Dessa forma, as normas indutoras não possuem categoria diversa das demais em se tratando de matéria tributária, mas sua diferenciação das outras normas consiste em sua função ou finalidade. A norma jurídica contém critérios objetivos e necessários para que dessa maneira seja possível a sua percepção no mundo jurídico, como exposto alhures. Entretanto, sua diferenciação de outras normas consiste em um critério finalístico, que por sua vez, pode ser buscado por uma análise quanto ao propósito que se pretende alcançar o legislador, o qual em cada traço dos contornos jurídicos do tributo revela-se o desejo deliberado de influir na ordem econômica e social, assim ter-

${ }_{5}^{5}$ SCHOUERI, Luís Eduardo. Normas Tributárias indutoras e intervenção econômica. Rio de Janeiro: Ed. Forense, 2005. P.12 
Artigo Original

Hegemonia - Revista Eletrônica do Programa de Mestrado em Direitos Humanos, Cidadania e Violência/Ciência Política do Centro Universitário Unieuro

ISSN: 1809-1261

UNIEURO, Brasília, número 27 (Especial), 2019, pp. 265-290.

se-ia a norma tributária indutora ${ }^{6}$.

Karl Friedrichs fazia referência ao fenômeno da norma tributária indutora, presente no que ele denominava de "impostos de consideração", cuja hipótese de incidência era formulada como meio de alcançar um fim, que poderia ser a melhora ou mesmo a manutenção da situação vigente ${ }^{7}$. Após a constatação que o tributo não se dava mais por razões arrecadatórias, o que não seria uma tarefa muito fácil, depreende-se que nada impedia o legislador, ainda que as necessidades do Estado estivessem resolvidas, introduzir novas espécies tributárias para que com isso exercesse a interferência na economia.

Por todo exposto, infere que o legislador tem ampla liberdade em matéria tributária no sentido de utilizar-se das normas indutoras, que são aquelas que servem como elementos operacionais e de interferência econômica para induzir o contribuinte a cumprir com a vontade do legislador. Em suma, mais que uma serventia de arrecadar, considerará o efeito socioeconômico dessa norma, em razão de existir dupla finalidade. Vale acrescentar que nessas normas implica a menor tributação, uma vez que o intuito primordial delas é adotar um comportamento tributado, sob análise a preservação ambiental.

\section{4 - O USO DA TRIBUTAÇÃO COMO FONTE INDUTORA DE COMPORTAMENTOS (FISCALIDADE X EXTRAFISCALIDADE)}

Examina-se mais uma vez a finalidade do tributo como instrumento de intervenção e arrecadação na análise dos reflexos da norma impositiva quanto à fiscalidade e extrafiscalidade. Desse modo, vejamos o entendimento do Celso de Barros acerca do tema:

Em primeiro lugar, a escolha do instrumento tributário como meio de financiamento do Estado define aquela que deve ser a função primeva das exações: a provisão de recursos públicos. Aqui está o cerne da noção de fiscalidade. O tributo é ferramenta de arrecadação e, na medida do possível, não deve interferir na capacidade produtiva e no equilíbrio concorrencial ${ }^{8}$.

\footnotetext{
${ }^{6}$ SCHOUERI, Luís Eduardo. Normas Tributárias indutoras e intervenção econômica. Rio de Janeiro: Ed. Forense, 2005. P.12.

${ }^{7}$ FRIEDRICHS, Karl, Apud: SCHOUERI, Luís Eduardo. Normas Tributárias indutoras e intervenção econômica. Rio de Janeiro: Ed. Forense, 2005. P.35

${ }^{8}$ CORREIA Neto, Celso de Barros. O Avesso do Tributo: Incentivos e Renúncias Fiscais no Direito Brasileiro. $2^{\mathrm{a}}$ Ed. São Paulo: Almedina, 2016.
} 
Artigo Original

Hegemonia - Revista Eletrônica do Programa de Mestrado em Direitos Humanos, Cidadania e Violência/Ciência Política do Centro Universitário Unieuro

ISSN: 1809-1261

UNIEURO, Brasília, número 27 (Especial), 2019, pp. 265-290.

Nisso, entretanto, não se esgota o instrumento tributário. Ao incidir sobre a atividade econômica, a tributação pode gerar e de fato gera resultados que vão além da obtenção de receitas públicas. Em especial, pode interferir na alocação de recursos econômicos e influir nos comportamentos no sistema fiscal, entre outras consequências possíveis, como exemplo condutas para a proteção dos recursos naturais.

Dessa maneira observa Luís Eduardo Shoueri:

A acepção de extrafiscalidade traz em seu bojo todo um conjunto de funções da norma diversa da mera fiscalidade, sendo mister, contudo, que se identifique, além da função arrecadadora e da extrafiscal, a categoria simplificadora. Esta última categoria é regida pelo princípio da praticabilidade, que permite a adoção de medidas globais, generalizantes, com o escopo de simplificar o sistema tributário?.

Assim, conclui o mencionado autor que a extrafiscalidade é um gênero que abarca todos os casos não vinculados à distribuição equitativa da carga tributária ou à simplificação do sistema tributário. Nessa senda, o gênero em foco incluiria as normas com a função indutora (que seria a extrafiscalidade em sentido estrito) e aquelas que também se moveriam por razões não fiscais, porém desatreladas da citada busca pelo impulso econômico por parte do Estado.

Sob o enfoque do conceito de extrafiscalidade, vale registrar a posição de Fábio Fanucchi, para quem há tributo extrafiscal quando se identificam, na sua cobrança, “outros interesses que não sejam os de simples arrecadação de recursos financeiros, exteriorizados mediante alívios e agravamentos fiscais ${ }^{10 \prime}$.

Outrossim, ao editar normas de direção, o Estado impõe determinado comportamento, isso faz com que não seja permitido outro tipo de conduta, senão aquele estabelecido na norma. Tratase de medida compulsória e a sua não observação faz surgir uma sanção jurídica. Já as normas de indução, o Estado não impõe comportamento algum, apenas privilegia ou desfavorece determinado comportamento, e faz com que este ou aquele comportamento seja economicamente

\footnotetext{
${ }^{9}$ SCHOUERI, Luís Eduardo. Normas Tributárias indutoras e intervenção econômica. Rio de Janeiro: Ed. Forense, 2005.

${ }^{10}$ BRANDÃO, Renata. Incentivo fiscal ambiental parâmetros e limites para sua instituição a luz da constituicão federal de 88 . Tese (Doutorado em Direito) - Programa de pós-graduação em Direito, Faculdade de Direito da Universidade de São Paulo, São Paulo, 2013.
} 
Artigo Original

Hegemonia - Revista Eletrônica do Programa de Mestrado em Direitos Humanos, Cidadania e Violência/Ciência Política do Centro Universitário Unieuro

ISSN: 1809-1261

UNIEURO, Brasília, número 27 (Especial), 2019, pp. 265-290.

mais vantajoso ou oneroso. Em um sentido mais amplo, é o que se convencionou chamar de extrafiscalidade ou normas tributárias indutoras, ou mesmo normas de finalidade social.

Nesse contexto, tanto as normas de indução como as extrafiscais atualmente não são vistas apenas como utensílio de obtenção de receitas públicas, como já citado no presente artigo, mas também com a consecução de outras finalidades. São normas intervencionistas e que direcionam outras espécies de políticas atingindo assim o interesse público e o bem comum dos contribuintes.

O efeito de indução acontece quando a hipótese de incidência está relacionada com uma conduta do contribuinte, dando origem à obrigação tributária, que uma vez praticada determinada condução incide a relação jurídica. Assim sendo, esta conduta pode vir a ser estimulada ou não pelo fisco, portanto, o efeito indutor somente ocorre na possibilidade de influência sobre o comportamento do contribuinte. A título de exemplo, observa-se acerca da redução do consumo de tabaco, onde se aumenta a alíquota com o intuito de desestimular o consumo.

Nessa esteira, defende Roque Carrazza que "há extrafiscalidade quando o legislador, em nome do interesse coletivo, aumenta ou diminui as alíquotas e/ou bases de cálculo dos tributos, com o objetivo principal de induzir os contribuintes a fazer ou deixar de fazer alguma coisa ${ }^{11}$ ".

Ressalta-se que a diferença entre a fiscalidade e a extrafiscalidade encontra-se no duplo propósito das normas extrafiscais, isto é, as normas fiscais tem o objetivo de arrecadar pecúnia para a manutenção do Estado, bem como através desses recursos ele consiga exercer suas atividades políticas, já as normas extrafiscais, além de obterem também essa função arrecadatória, tem o intuito de estimular determinadas condutas por meio da incidência tributária, ou seja, a extrafiscalidade consiste na produção de efeitos secundários.

Fincadas tais considerações sobre as normas fiscais e extra fiscais, cumpre pontuar que para fins do estudo ora empreendido, a tributação ambiental insere-se, precisamente, nesse contexto, isto é, o Estado utiliza-se do aparelho fiscal, do instrumento tributo, para alcançar um fim socialmente desejado, consiste na preservação, manutenção ou recuperação do meio ambiente ecológico. Segundo Juan Alabern, “atualmente, é impensável realizar um estudo sério sobre a extrafiscalidade sem abordar o tema da tributação ecológica, uma vez que essa matéria tem ocupado especial protagonismo nos últimos anos e, com o passar do tempo, a relevância do tema só tem

\footnotetext{
11 OLIVEIRA NETO, Alexandre. Compatibilidade de um tributo ambiental com o sistema tributário nacional. Dissertação (Mestrado em Direito) - Departamento de Direito Econômico, Financeiro e Tributário, Faculdade de Direito da Universidade de São Paulo - USP, São Paulo, 2014. P. 25
} 
Artigo Original

Hegemonia - Revista Eletrônica do Programa de Mestrado em Direitos Humanos, Cidadania e Violência/Ciência Política do Centro Universitário Unieuro

ISSN: 1809-1261

UNIEURO, Brasília, número 27 (Especial), 2019, pp. 265-290.

aumentado".

\section{5 - A PROTEÇÃO DO MEIO AMBIENTE NO BRASIL}

A Constituição Federal de 1988, sob influência da Declaração de Estocolmo de 1972, pela primeira vez na história trouxe um capítulo próprio sobre a proteção do meio ambiente ligada à qualidade de vida, o qual se encontra no Capítulo VI, art. 225. Assim, estabeleceu-se diretriz e princípios para a preservação dos recursos naturais, conforme se percebe no mencionado artigo:

Art. 225. Todos têm direito ao meio ambiente ecologicamente equilibrado, bem de uso comum do povo e essencial à sadia qualidade de vida, impondo-se ao Poder Público e à coletividade o dever de defendê-lo e preservá- lo para as presentes e futuras gerações.

O referido artigo da Carta maior exerce papel norteador do meio ambiente mensurado pela obrigação de o Estado e de a sociedade garantirem um meio ambiente ecologicamente equilibrado. Além disso, o bem ambiental é um bem de uso comum do povo e essencial à qualidade de vida, bem como é dever de todos zelar, cuidar, preservar esses bens.

Sobre a proteção constitucional ao meio ambiente, José Rubens Morato Leite aduz que:

Em termos formais, a proteção do meio ambiente na Constituição de 1988 não segue nem seria recomendável que seguisse um único padrão normativo, dentre aqueles encontráveis no Direito Comparado. Ora o legislador utiliza-se da técnica do estabelecimento de direito e dever genéricos (por ex.. a primeira parte do artigo 225, caput, ora faz uso da instituição de deveres especiais (p. ex., todo o artigo $225, \mathbb{\Omega} 1^{\circ}$.). Em alguns casos, tais enunciados normativos podem ser apreciados como princípios específicos e explícitos (p. ex., os princípios da função ecológica da propriedade rural e do poluidor-pagador, previstos, respectivamente, nos artigos. 186, II, e 225, \\ 22 e 32), noutros, como instrumentos de execução (p. ex., a previsão do Estudo Prévio de Impacto Ambiental ou da ação civil pública). O constituinte também protegeu certos biomas hiperfrágeis ou de grande valor ecológico (p. ex., a Mata Atlântica, o Pantanal, a Floresta Amazônica, a Serra do Mar e a Zona Costeira) ${ }^{12}$.

Com esse movimento de constitucionalização do meio ambiente, firma-se também uma

${ }^{12}$ CANOTILHO, José Joaquim; LEITE, José Rubens Morato (organizadores). Direito constitucional ambiental brasileiro. São Paulo: Saraiva, 2007. 
Artigo Original

Hegemonia - Revista Eletrônica do Programa de Mestrado em Direitos Humanos, Cidadania e Violência/Ciência Política do Centro Universitário Unieuro

ISSN: 1809-1261

UNIEURO, Brasília, número 27 (Especial), 2019, pp. 265-290.

nova postura (uma nova ética), através da qual a fria avaliação econômica dos recursos ambientais perde sua primazia exclusivista e individualista, uma vez que precisa ser sempre contrabalançada com a saúde dos cidadãos, com as expectativas das futuras gerações, com a manutenção das funções ecológicas, com os efeitos em longo prazo da exploração e com os benefícios do uso limitado (e até do não uso) da natureza.

José Afonso da Silva é mais enfático e assevera que é importante que se tenha consciência de que o direito à vida, como base de todos os demais direitos fundamentais do homem, é o que deve orientar todas as formas de atuação no campo da tutela do meio ambiente ${ }^{13}$.

Desse modo, outro dispositivo de extrema importância é o artigo 170 da CF/88. Nele estão gravados os princípios que regem a Ordem Econômica. Um desses princípios é o da defesa do meio ambiente que teve sua redação modificada e ampliada pela emenda constitucional $n^{\circ}$ $42 / 03$.

Desta feita, comentando o referido dispositivo, André Ramos Tavares entende que a exploração dos recursos naturais necessários ao desenvolvimento econômico do país deve ser pautada pelas diretrizes do chamado desenvolvimento sustentável, oposto, portanto, da devastação ambiental inconsequente e excessiva.

Para o jurista Eros Roberto Grau, o princípio veiculado pelo art. 170, VI da CF/88, é um princípio constitucional do tipo impositivo, segundo classificação do constitucionalista Gomes Canotilho. Este autor português defende que os princípios constitucionais impositivos são aqueles que obrigam os órgãos do Estado, sobretudo o legislador, à realização de fins e à execução de tarefas. Dinâmicos e prospectivamente orientados, são preceitos definidores do fim do Estado ${ }^{14 .}$

Não obstante essa constatação, razões várias recomendam a constitucionalização do ambiente, podendo ser esta considerada uma tendência mundial irreversível, o que certamente não passou despercebido ao constituinte brasileiro de 1988.

Por tudo quanto exposto, compreende-se que após a promulgação da Constituição Federal

\footnotetext{
13 SILVA, José Afonso, Apud: OLIVEIRA NETO, Alexandre. Compatibilidade de um tributo ambiental com o sistema tributário nacional. Dissertação (Mestrado em Direito) - Departamento de Direito Econômico, Financeiro e Tributário, Faculdade de Direito da Universidade de São Paulo - USP, São Paulo, 2014. P.45

${ }^{14}$ BRANDÃO, Renata. Incentivo fiscal ambiental parâmetros e limites para sua instituição a luz da constituição federal de 88. Tese (Doutorado em Direito) - Programa de pós-graduação em Direito, Faculdade de Direito da Universidade de São Paulo, São Paulo, 2013.
} 
Artigo Original

Hegemonia - Revista Eletrônica do Programa de Mestrado em Direitos Humanos, Cidadania e Violência/Ciência Política do Centro Universitário Unieuro

ISSN: 1809-1261

UNIEURO, Brasília, número 27 (Especial), 2019, pp. 265-290.

de 1988, passou-se a ter uma tutela como direito fundamental ao meio ambiente. Assim, sendo os recursos naturais importantes e parte do patrimônio histórico cultural brasileiro, bem como sendo aspectos que agregam qualidade de vida para todos os cidadãos, o legislador entendeu e estabeleceu uma norma de proteção ao meio ambiente. Nesse sentido, trata-se de um direito humano fundamental, o qual tem uma dimensão ecológica e econômica que devem se harmonizar sob o conceito do desenvolvimento sustentável e dentro dos parâmetros da ordem econômica e das normas constitucionais.

Deste modo, o meio ambiente foi e continua sendo uma preocupação, e as normas existem como finalidade de resguardar a utilização dos recursos naturais, como, por exemplo, o solo, a água, os animais e as florestas.

Diante dessa realidade, essa preocupação foi aumentando quando se percebeu que os bens ambientais estavam tornando-se limitados com o passar do tempo, pois havia alguns que tinham sua qualidade diminuída com a degradação do homem. O meio ambiente precisa cada vez mais de proteção devido o crescimento exagerado dos atos de impactos, como por exemplo, a atual crise hídrica. Ela traz uma reflexão quanto ao já exposto e deixa claro que o meio ambiente também tem suas limitações.

6 - A IMPORTÂNCIA DA SUSTENTABILIDADE PARA O PRESENTE E FUTURAS GERAÇÕES

$\mathrm{Na}$ busca pela preservação do meio ambiente, diante das grandes devastações que são provocadas, surge à sustentabilidade. A sustentabilidade apresenta-se como promovedora de um desenvolvimento ético, que se dá ao mesmo tempo em que acontece o desenvolvimento dos países. No entanto, não só o desenvolvimento será capaz de suprir as necessidades da humanidade, pois a obtenção dos recursos para este é retirado do meio ambiente, imprescindível para a forma de vida humana.

Diante da necessidade da sustentabilidade, assevera Sueli Norma Padilha citada por Enrique Leff, in verbis:

[..] a sustentabilidade aparece como uma necessidade de restabelecer o lugar da natureza na teoria economia e nas práticas de desenvolvimento, internalizando condições 
Artigo Original

Hegemonia - Revista Eletrônica do Programa de Mestrado em Direitos Humanos, Cidadania e Violência/Ciência Política do Centro Universitário Unieuro

ISSN: 1809-1261

UNIEURO, Brasília, número 27 (Especial), 2019, pp. 265-290.

ecológicas da produção que assegurem a sobrevivência e um futuro para humanidade ${ }^{15}$.

A Comissão Mundial sobre o meio ambiente e desenvolvimento da Organização das Nações Unidas, por intermédio do documento Our Common Future, de 1987, também conhecido como Relatório Brundtland, definiu que o desenvolvimento sustentável seria aquele que satisfaz as necessidades presentes, sem comprometer a capacidade das gerações futuras de suprir suas próprias necessidades.

Ainda, sobre a concepção de desenvolvimento sustentável na ótica de um conceito mais amplo, traz o Relatório de Bruntland:

[...] é um processo de transformação no qual a exploração de recursos, a direção dos investimentos, a orientação do desenvolvimento tecnológico a mudança institucional se harmonizam e reforçam o potencial presente e futuro, a fim de atender às necessidades e aspirações humanas.

Nessa perspectiva, a sustentabilidade apresenta-se como um conceito que tem como principal objetivo a garantia do meio ambiente. Nestes termos, para haver condição de vida é necessário os recursos naturais, que podem vir a se extinguir se não forem explorados de forma sustentável. Sendo assim, a proposta trazida pela sustentabilidade se mostra como forma de promover a existência e garantir o futuro das próximas gerações.

Perante o exposto, compreende-se que a manutenção da ecologia é essencial para a vida e também para não comprometer o futuro das próximas gerações, pois, a natureza não é infinita e cada vez mais precisa ser utilizada de maneira inteligente, para que assim se mantenham no futuro como fonte de qualidade de vida.

Dessa maneira, a sustentabilidade visa conscientizar a preservação do meio ambiente para que este permaneça de gerações a gerações. Inclusive porque, com o meio ambiente degradado, o ser humano abrevia o seu tempo de vida, a economia não se desenvolve e o futuro fica insustentável.

${ }^{15}$ RONCONI, Elizangela Pieta; POFFO, Gabriella Depiné. Sustentabilidade: O Caminho para as presentes e futuras gerações. In: DIREITO E SUSTENTABILIDADE. 1. [Recurso eletrônico on-line] organização CONPEDI/UFSC; coordenadores: Carlos André Hüning Birnfeld, Álvaro Gonçalves Antunes Andreucci, Luiz Ernani Bonesso de Araujo. Florianópolis: CONPEDI, 2014. Disponível em: <http://publicadireito.com.br/publicacao/ufsc/livro.php?gt=209>. Acesso em: 13 de outubro de 2017. 
Artigo Original

Hegemonia - Revista Eletrônica do Programa de Mestrado em Direitos Humanos, Cidadania e Violência/Ciência Política do Centro Universitário Unieuro

ISSN: 1809-1261

UNIEURO, Brasília, número 27 (Especial), 2019, pp. 265-290.

\section{7 - A DEFESA DO MEIO AMBIENTE NA ORDEM ECONÔMICA}

Em busca de prosperidade, as sociedades transformam a natureza em recurso do processo produtivo e, submetendo a ordem ecológica à ordem econômica, dilapidam os serviços ecossistêmicos, suporte da vida neste planeta. $\mathrm{O}$ mundo em que se vive encontra-se abarrotado pelas externalidades resultantes do processo econômico de crescimento. Entropização dos processos produtivos, alteração do equilíbrio ecológico, destruição de ecossistemas, esgotamento de recursos naturais, extinção de espécies, aquecimento global, desigualdade social, pobreza extrema são problemas que desenham uma crise ecológica há pouco reconhecida, e constantemente evitada ${ }^{16}$.

A relação homem-natureza é essencialmente norteada por uma razão utilitarista, de apropriação, no âmbito da qual o natural se torna instrumento de saciedade das necessidades do ser humano, que em verdade, sequer deseja compreendê-lo. Assim, sob uma conceituação antrópica, a natureza se torna mero recurso para a produção econômica.

Dessa forma, e a partir da compreensão humana da natureza, enquanto âmbito que circula o objeto e suporta a sua existência, que se desenvolve o conceito, ainda novo, de meio ambiente, definido por Cristiane Derani como "o conjunto das condições de existência humana, que integra e influencia o relacionamento entre os homens, sua saúde e seu desenvolvimento" ${ }^{17}$.

Portanto, a República Federativa do Brasil ao listar seus objetivos, como, por exemplo, a construção de uma sociedade livre, justa e solidária, o desenvolvimento nacional, a erradicação da pobreza, a redução das desigualdades sociais e a promoção do bem de todos, em evidente rompimento com a ideologia suporte da ordem procedente, não poderia deixar de estabelecer, através da Constituição de 1988, um conjunto de normas de hierarquia superior que reorganizasse o relacionamento do ser humano com a natureza, eis que todos os aspectos da vida social se relacionam de alguma forma, com o todo que os envolve.

\footnotetext{
${ }^{16}$ SORIANO, Kelly Schaper. A Defesa do meio ambiente na ordem econômica constitucional brasileira: $O$ direito por uma economia ecológica. Dissertação (Mestrado em Direito) - Centro de Ciências Jurídicas, Programa de Pós-Graduação em Direito, Universidade Federal de Santa Catarina, Florianópolis, 2014.

${ }^{17}$ SORIANO, Kelly Schaper. A Defesa do meio ambiente na ordem econômica constitucional brasileira: O direito por uma economia ecológica. Dissertação (Mestrado em Direito) - Centro de Ciências Jurídicas, Programa de Pós-Graduação em Direito, Universidade Federal de Santa Catarina, Florianópolis, 2014.
} 
Artigo Original

Hegemonia - Revista Eletrônica do Programa de Mestrado em Direitos Humanos, Cidadania e Violência/Ciência Política do Centro Universitário Unieuro

ISSN: 1809-1261

UNIEURO, Brasília, número 27 (Especial), 2019, pp. 265-290.

No Brasil, certo de que a mudança de paradigma no sentido da construção de um mundo sustentável não poderia ser promovida apenas pelo Estado, o constituinte inseriu o princípio da defesa do meio ambiente no âmbito da ordem econômica constitucional, imbuindo à atividade econômica nacional, pública e privada, da preocupação ecológica que caracteriza todo o texto da Carta Maior. Sendo assim, o artigo 170 da Constituição apresenta os princípios gerais da atividade econômica, estabelecendo que:

Art. 170. A ordem econômica, fundada na valorização do trabalho humano e na livre iniciativa, tem por fim assegurar a todos existência digna, conforme os ditames da justiça social, observados os seguintes princípios: I - soberania nacional; II - propriedade privada; III - função social da propriedade; IV - livre concorrência; V - defesa do consumidor; VI - defesa do meio ambiente, inclusive mediante tratamento diferenciado conforme 0 impacto ambiental dos produtos e serviços e de seus processos de elaboração e prestação; (Redação dada pela Emenda Constitucional n ${ }^{\circ} 42$, de 19.12.2003); VII - redução das desigualdades regionais e sociais; VIII - busca do pleno emprego; IX - tratamento favorecido para as empresas de pequeno porte constituídas sob as leis brasileiras e que tenham sua sede e administração no País. (Redação dada pela Emenda Constitucional n ${ }^{\circ}$ 6, de 1995); Parágrafo único. É assegurado a todos o livre exercício de qualquer atividade econômica, independentemente de autorização de órgãos públicos, salvo nos casos previstos em lei (grifo nosso).

Nessa perspectiva, a inclusão do respeito ao meio ambiente no núcleo de princípios fundamentais da ordem econômica representa um marco fundamental no Direito Econômico Brasileiro, pois confere a mais alta hierarquia normativa à máxima que impõe às atividades econômicas o respeito aos limites da natureza. É a conformação da ordem econômica às regras da Terra.

Nesta esteira, afirma Paulo de Bessa Antunes:

A inclusão do "respeito ao meio ambiente" como um dos princípios da atividade econômica e financeira é medida de enorme importância, pois ao nível mais elevado de nosso ordenamento jurídico está assentado que a licitude constitucional de qualquer atividade fundada na livre iniciativa está, necessariamente, vinculada à observância do respeito ao meio ambiente ou, em outras palavras, à observância das normas de proteção ambiental vigente ${ }^{18}$.

18 ANTUNES, Paulo de Bessa, Apud: SORIANO, Kelly Schaper. A Defesa do meio ambiente na ordem econômica constitucional brasileira: O direito por uma economia ecológica. Dissertação (Mestrado em Direito) - Centro de Ciências Jurídicas, Programa de Pós-Graduação em Direito, Universidade Federal de Santa Catarina, Florianópolis, 2014. 
Artigo Original

Hegemonia - Revista Eletrônica do Programa de Mestrado em Direitos Humanos, Cidadania e Violência/Ciência Política do Centro Universitário Unieuro

ISSN: 1809-1261

UNIEURO, Brasília, número 27 (Especial), 2019, pp. 265-290.

Nessa lógica, percebe-se que é preciso garantir um desenvolvimento econômico sustentável, haja vista que a economia depende do meio ambiente para se desenvolver. Este desenvolvimento é necessário para a sociedade, mas esta sociedade depende da natureza para sobreviver. Dessa forma, se está diante de um ciclo evolutivo, pois sem a natureza não existe humanidade, nem tampouco o desenvolvimento, evidenciando-se assim a importante missão de que é preciso garantir proteção à natureza para continuar o crescimento, tendo como pilar a sustentabilidade ${ }^{19}$.

Pelo apresentado, identifica-se que o meio ambiente faz parte da economia, sendo assim, uma economia sustentável proporciona qualidade de vida e preservação dos recursos naturais, de maneira que o ecossistema continue a satisfazer as necessidades do homem por um longo tempo.

\section{8 - A RELAÇÃO DO DIREITO TRIBUTÁRIO COM O DIREITO AMBIENTAL}

O direito tributário se relaciona com o direito ambiental, assim como o faz com outras disciplinas como, por exemplo, o direito civil, constitucional, administrativo e etc. Além disso, a Constituição de 1988 foi a primeira a tratar da questão ambiental, sendo considerada uma das mais avançadas em matéria de tutela ambiental, logo, ela traz uma perspectiva de necessidade de proteção ao meio ambiente, conforme previsto no artigo 225 e 170 da CF/88.

Diante disso, percebe-se que a ecologia e a economia têm conceitos distintos, entretanto, ambos caminham em sinergia. Assim, não há que se falar em searas distintas e inconciliáveis, pois o direito age por meio da interdisciplinaridade também com o direito ambiental.

Desse modo, o sistema tributário destaca-se como um instrumento estatal no que tange a sua função extrafiscal, mecanismo importantíssimo no combate à degradação do meio ambiente. Isso porque para a constituição de um meio ambiente ecologicamente equilibrado e saudável faz-se necessário à implantação também de uma economia sustentável que respeite as diretrizes desse direito fundamental.

${ }^{19}$ SORIANO, Kelly Schaper. A Defesa do meio ambiente na ordem econômica constitucional brasileira: O direito por uma economia ecológica. Dissertação (Mestrado em Direito) - Centro de Ciências Jurídicas, Programa de Pós-Graduação em Direito, Universidade Federal de Santa Catarina, Florianópolis, 2014. 
Artigo Original

Hegemonia - Revista Eletrônica do Programa de Mestrado em Direitos Humanos, Cidadania e Violência/Ciência Política do Centro Universitário Unieuro

ISSN: 1809-1261

UNIEURO, Brasília, número 27 (Especial), 2019, pp. 265-290.

\section{9 - TRIBUTAÇÃO, MEIO AMBIENTE E EXTRAFISCALIDADE}

Para a concretização do direito fundamental ao meio ambiente é necessário que o Estado intervenha na ordem econômica a fim de implementar políticas ambientais, que redirecionem a racionalidade da iniciativa privada e consumidores a práticas ambientalmente desejáveis.

Para tal finalidade, enfatiza-se a eficiência dos instrumentos econômicos por intermédio dos institutos do direito tributário ambiental. Por meio da instituição de tributos ou pela concessão de benefícios fiscais é possível a indução a práticas ambientalmente adequadas. Constata que a política tributária ambiental no Brasil deve ocorrer por intermédio de benefícios fiscais, instrumentos mais apropriados para desestimular a poluição e fomentar práticas ambientais responsáveis ${ }^{20}$.

Atualmente, além da mera função arrecadatória de recursos para o Estado, que é presente nos tributos, há a coexistência da extrafiscalidade com a fiscalidade. Nessa perspectiva, destaca-se a lição de Alfredo Augusto Becker sobre a finalidade dos tributos:

\footnotetext{
Não será a de um instrumento de arrecadação de recursos para o custeio das despesas públicas, mas a de um instrumento de intervenção estatal no meio social e na economia privada. $\mathrm{Na}$ construção de cada tributo não mais será ignorado o finalismo extrafiscal, nem será esquecido o fiscal. Ambos coexistirão agora de um modo consciente e desejado; apenas haverá maior ou menor prevalência deste ou daquele finalismo ${ }^{21}$.
}

Nessa continuidade, o exemplo de tributação socioambiental está consubstanciado na extrafiscalidade, real ferramenta na execução dos efeitos que enseja o constituinte. Logo se percebe que a atividade econômica é intrinsecamente ligada à ecologia. Assim, concentra-se a tutela do Estado tanto no meio ambiente como na economia na busca de um plano de efeitos aos quais atinge o comportamento do contribuinte, através das normas tributárias, sendo essas condutas estimuladas ou não para que o Estado assim atue de forma imprescindível na preservação do meio ambiente.

\footnotetext{
${ }^{20}$ CIRINO, Samia Moda; BASSOLI, Marlene Kempfer. Direito Tributário Ambiental: Benefícios Fiscais às Empresas para a Proteção do Direito Fundamental ao Meio Ambiente. V. 12, Londrina: Scientia Iuris, 2008. Disponível em: <http://www.uel.br/revistas/uel/index.php/iuris/article/view/4168/3619>. Acesso em: 10 de novembro de 2017

${ }^{21}$ BECKER, Alfredo Augusto, Apud: NUNES, Cleucio Santos. Direito tributário e meio ambiente. São Paulo: Dialética, 2005
} 
Artigo Original

Hegemonia - Revista Eletrônica do Programa de Mestrado em Direitos Humanos, Cidadania e Violência/Ciência Política do Centro Universitário Unieuro

ISSN: 1809-1261

UNIEURO, Brasília, número 27 (Especial), 2019, pp. 265-290.

Igualmente, é possível citar como exemplo dessa visão crescente os tributos verdes, com evidente característica extrafiscal socioambiental, já que a socioambientalidade está ligada diretamente ao correto desenvolvimento da sociedade, protegidas por medidas ambientalmente orientadas.

No Brasil, a tributação extrafiscal socioambiental abraçou a Green Taxes (Tributo Verde), que proporcionam aproximação do sistema tributário brasileiro frente às perspectivas ambientais da sustentabilidade, lembrando que a proteção ambiental, em virtude das peculiaridades do Brasil, já havia sido objeto de tributos extrafiscais, como a criação de incentivos tributários com finalidades ambientais e elementos da configuração do tributo ambiental. Nesse sentido, o art. 170 da CF/88 contribui de maneira incisiva ao desenvolvimento das Green Taxes ao anexar dentro dos princípios gerais que orientam a atividade econômica, a proteção ao meio ambiente ${ }^{22 .}$

Consubstanciado da mesma forma para o papel relevante das Green Taxes, além do art. 170, também contribui o art. 225 da CF/88, relativo ao meio ambiente. Por isso, a necessidade de se garantir o direito ao meio ambiente à coletividade o dever de defendê-lo e preservá-lo para que as gerações futuras possam desfrutar do meio ambiente protegido.

Evidencia-se, assim, que esta ideia está atrelada à noção de sustentabilidade, ou desenvolvimento sustentável, o que demonstra a grande influência daquelas conferências internacionais na elaboração do dispositivo. São, portanto, dois dispositivos constitucionais que se reputam essenciais no estudo jurídico desses instrumentos tributários no ordenamento jurídico brasileiro.

De qualquer modo, podemos afirmar que a extrafiscalidade socioambiental estará inevitavelmente inserida nos próximos anos com maior força no sistema tributário nacional. Isso porque, a socioambientalidade está prevista nos atuais projetos de Reforma Tributária. Pode-se confirmar pela leitura do projeto, que já existem importantes alterações a serem realizadas no regime tributário das Green Taxes brasileiras e, consequentemente, representando o passo adiante no que diz respeito à extrafiscalidade socioambiental.

Portanto, com isso tem-se o direito tributário que por meio de normas extrafiscais visa alterar ou induzir comportamentos com o fim de alcançar os interesses sociais e principalmente ambientais

\footnotetext{
${ }^{22}$ MOREIRA, Rafael Soares. Tributação Extrafiscal e Meio Ambiente: Rumo a Concepção de Tributo Ambiental. Monografia (Bacharel em Ciências Jurídicas e Sociais) - Graduação em Ciências Jurídicas e Sociais, Pontifícia Universidade Católica do Rio Grande do Sul, Rio Grande do Sul, 2011. P. 06
} 
Artigo Original

Hegemonia - Revista Eletrônica do Programa de Mestrado em Direitos Humanos, Cidadania e Violência/Ciência Política do Centro Universitário Unieuro

ISSN: 1809-1261

UNIEURO, Brasília, número 27 (Especial), 2019, pp. 265-290.

disposto na Constituição Federal. Os artigos constitucionais asseveram que o tributo não tem o propósito de obstruir a iniciativa econômica por terem sua proteção na própria Carta Magna, porém, a extrafiscalidade contribui para as políticas públicas voltadas a preservação do meio ambiente, uma vez que dificilmente outras áreas do direito conseguiriam alcançar. Esse intervencionismo estatal não derruba os pilares do capitalismo, apenas positiva uma condução mais favorável à sustentabilidade, tendo em vista que os avanços da economia devem frisar os limites da natureza como medida acautelatória de perpetuidade.

\section{0 - RENUNCIAS DE RECEITAS E OS INCENTIVOS FISCAIS AMBIENTAIS}

O conceito de extrafiscalidade abre o discurso jurídico do tributo para elementos que, em princípio, estariam além da obrigação tributária. Entretanto, observa-se um aspecto positivo no campo da extrafiscalidade no que tange a amenização dos problemas ambientais.

Nessa acepção, o que se pretende dizer é que, é nesse espaço que se inserem as questões atinentes às finalidades e aos efeitos das exações e, por conseguinte, é também nele que se situam os incentivos e renúncias fiscais. Ambas as noções, de uma forma ou de outra, sempre remetem a análise jurídica a situações nas quais se reduz ou se elimina o tributo com objetivos que não dizem respeito estrita e diretamente à arrecadação, ou seja, objetivos extrafiscais.

O campo da extrafiscalidade, como já demonstrado, é o espaço designado para a maior parte desses temas, inclusive os problemas jurídicos suscitados pela concessão de incentivos fiscais. Sua análise contribui, destarte, para esclarecer como o Estado utiliza esse mecanismo com o fim de tentar amenizar os impactos que permeiam a sociedade brasileira.

A expressão "renúncia de receita" e "renúncia fiscal", embora nestas o contrassenso não seja tão evidente, não há estritamente renúncia alguma, nem de competência, nem de receita. A renúncia é antes (resultado de) seu exercício, ainda que para afastar total ou parcialmente a cobrança de certa exação. Só quem pode cobrar o tributo pode renunciá-lo.

Da mesma maneira, não há também renúncia à receita tributária propriamente dita. A renúncia, como ato jurídico, é praticada pelo titular de um direito no sentido de extinguir relação jurídica pré-estabelecida e desobrigar o sujeito passivo da relação de crédito. Em outras palavras, renunciando, o credor perdoa graciosamente a dívida, abre mão de seu direito e põe fim à obrigação antes instalada. 
Artigo Original

Hegemonia - Revista Eletrônica do Programa de Mestrado em Direitos Humanos, Cidadania e Violência/Ciência Política do Centro Universitário Unieuro

ISSN: 1809-1261

UNIEURO, Brasília, número 27 (Especial), 2019, pp. 265-290.

Nesse ponto de vista, embora o Código Tributário Nacional e o Código Civil de 2002 não incluam a renúncia entre as modalidades de extinção das obrigações, ambos preveem a remissão como modalidade graciosa de extinção da obrigação, nos artigos 172 e 385, respectivamente. Na essência, renúncia e remissão têm o mesmo conteúdo: há uma relação jurídica obrigacional preexistente que se extingue, por decisão do credor, sem que a prestação efetive-se.

O fato é que essa relação jurídica preexistente não costuma se observar nos casos de renúncia fiscal. Na maior parte das situações acolhidas pelo ordenamento jurídico, como renúncia de receita tributária, notadamente as mencionadas no art. 14 da Lei Complementar n. 101 de 200, não se verifica exatamente a existência de uma prévia relação de crédito tributário de que abra mão o legislador. Como o ato legislativo, a renúncia, não raro, precede inclusive a ocorrência do fato gerador e, portanto, o surgimento do crédito tributário.

Buscando maior exatidão, destaca-se que apenas nos casos de remissão e anistia é que o débito precede a renúncia, mas certamente nenhuma interpretação que se conhece pretende que a noção e exame fiquem restrita a esses dois institutos. Assim, a Lei de Responsabilidade Fiscal limita a ação do legislador na concessão de incentivos de natureza tributária nos termos do art. 14, que assim prescreve:

Art. 14. A concessão ou ampliação de incentivo ou benefício de natureza tributária da qual decorra renúncia de receita deverá estar acompanhada de estimativa do impacto orçamentário-financeiro no exercício em que deva iniciar sua vigência e nos dois seguintes, atender ao disposto na lei de diretrizes orçamentárias e a pelo menos uma das seguintes condições:

(...)

$\int 1^{\circ}$ A renúncia compreende anistia, remissão, subsídio, crédito presumido, concessão de isenção em caráter não geral, alteração de alíquota ou modificação de base de cálculo que implique redução discriminada de tributos ou contribuições, e outros benefícios que correspondam a tratamento diferenciado.

Já foi mencionado que os incentivos fiscais não passam, grosso modo, de exonerações extrafiscais, concedidas com vistas à produção de efeitos não financeiros. O instituto da exoneração tributária é certamente tão antigo quanto à própria ideia de tributo. Onde quer que tenham sido instituídos e cobrados, existiu também previsão de que certos fatos ou sujeitos deveriam escapar à incidência tributária e ficar livres desse ônus.

Não parece que o peso e o impacto social e econômico dos tributos tenham sido jamais 
Artigo Original

Hegemonia - Revista Eletrônica do Programa de Mestrado em Direitos Humanos, Cidadania e Violência/Ciência Política do Centro Universitário Unieuro

ISSN: 1809-1261

UNIEURO, Brasília, número 27 (Especial), 2019, pp. 265-290.

ignorados, tampouco a maneira como a redução da carga fiscal poderia favorecer certos sujeitos, classes ou atividades. Tudo indica que a exigência de tributos e sua exoneração tenham sempre convivido nos diferentes sistemas fiscais. Todavia, nem todas essas situações nas quais se afasta ou se reduz a incidência fiscal podem, de fato, ser tomadas como incentivo ou benefício fiscal, segundo sua concepção.

A propósito, salienta Norberto Bobbio:

[...] desde que o Estado assume a tarefa, não só de controlar o desenvolvimento econômico, mas também de dirigi-lo, o instrumento idôneo para essa função não é mais a norma reforçada por uma sanção negativa contra aqueles que a transgridem, mas a diretriz econômica que, com frequência, é reforçada por uma sanção positiva em favor daqueles que a ela se conformam, como acontece, por exemplo, nas chamadas leis de incentivo, que começam a ser estudadas pelos juristas ${ }^{23}$.

No Estado contemporâneo, explica Norberto Bobbio, “o direito já não se limita a tutelar ato conformes às próprias normas, mas tende a estimular atos inovadores". Além do tipo de controle passivo, que se ocupa em desfazer ou reagir às condutas indesejáveis, tornando-as impossíveis, mais difíceis ou desvantajosas, passa-se ao controle ativo, que procura intervir também positivamente: faz das ações desejadas necessárias, mais fáceis ou vantajosas para quem às pratica ${ }^{24}$

As leis de incentivos fiscais incluem-se entre as técnicas de encorajamento que ganham maior destaque nesse contexto. Não se resumem, evidentemente, à mera redução da carga fiscal, carregam em si uma decisão que deve estar comprometida com a concretização dos valores e objetivos consagrados pela ordem jurídica. São "leis de impulsão": "destinam-se a servir de instrumento para a realização de determinadas metas, de uma política". Explica Regis Fernandes de Oliveira, a propósito das razões que orientam a concessão de desonerações fiscais:

O normal de qualquer governante é que diligencie o recebimento de todas as receitas. Com elas é que pode atingir as metas a que se propôs e prestar bons serviços à coletividade a que deve servir. Ocorre que, por razões políticas, até importantes, o governante é levado a abrir mão de

${ }^{23}$ CORREIA Neto, Celso de Barros. O Avesso do Tributo: Incentivos e Renúncias Fiscais no Direito Brasileiro. $2^{\mathrm{a}}$ Ed. São Paulo: Almedina, 2016. P.92

${ }^{24}$ CORREIA Neto, Celso de Barros. O Avesso do Tributo: Incentivos e Renúncias Fiscais no Direito Brasileiro. $2{ }^{a}$ Ed. São Paulo: Almedina, 2016. P.92 
Artigo Original

Hegemonia - Revista Eletrônica do Programa de Mestrado em Direitos Humanos, Cidadania e Violência/Ciência Política do Centro Universitário Unieuro

ISSN: 1809-1261

UNIEURO, Brasília, número 27 (Especial), 2019, pp. 265-290.

parte da sua arrecadação para estimular outras políticas ${ }^{25}$.

Nessa acepção, José Casalta Nabais conceitua os incentivos fiscais como "medidas de caráter excepcionais instituídas para tutela de interesses públicos extrafiscais relevantes e que sejam superiores aos da própria tributação que impede ${ }^{26 ”}$.

De fato, os incentivos fiscais irão consubstanciar tratamento tributário abrandado, concedidos por meio de lei específica para tal fim, a um grupo de contribuintes, com intuito de alcançar o crescimento econômico, o aumento de saldo da balança comercial, o desenvolvimento do parque industrial nacional, a criação de vínculos formais de empregos, o incremento da competitividade dos produtos de fabricação nacional no mercado interno e externo, a proteção do meio ambiente e etc.

Diante disso, a renúncia e os incentivos fiscais também atuam na seara ambiental, servindo de instrumentos de diminuição e interrupção da degradação dos recursos naturais. Destarte, a concessão desses institutos concederá uma diminuição, remissão ou isenção na carga tributária para que o contribuinte em contrapartida adote uma política e/ou conduta sustentável. Entretanto, observados o previsto na legislação, essa diminuição feita quanto ao interesse ambiental também poderá aumentar a tributação dos mais poluentes. Um exemplo que deixa claro essa situação seria no caso de aumento de alíquota de extração de madeira, para que essa tributação majorada desestimule a prática desse tipo de serviço.

\section{1- RESULTADOS PRÁTICOS DAS INTERVENÇÕES ESTATAIS NO MEIO AMBIENTE SOB O PONTO DE VISTA DA TRIBUTAÇÃO}

Como visto a tributação também pode ser abarcada para a preservação do meio ambiente. Posto isso, nota-se, também, através das pesquisas realizadas que, além do Brasil, vários outros países adotaram políticas públicas por meio da tributação extrafiscal com o intuito de se alcançar o

\footnotetext{
${ }^{25}$ CORREIA Neto, Celso de Barros. O Avesso do Tributo: Incentivos e Renúncias Fiscais no Direito Brasileiro. $2^{\text {a }}$ Ed. São Paulo: Almedina, 2016. P.130

${ }^{26}$ BRANDÃO, Renata. Incentivo fiscal ambiental parâmetros e limites para sua instituição a luz da constituição federal de 88 . Tese (Doutorado em Direito) - Programa de pós-graduação em Direito, Faculdade de Direito da Universidade de São Paulo, São Paulo, 2013.
} 
Artigo Original

Hegemonia - Revista Eletrônica do Programa de Mestrado em Direitos Humanos, Cidadania e Violência/Ciência Política do Centro Universitário Unieuro

ISSN: 1809-1261

UNIEURO, Brasília, número 27 (Especial), 2019, pp. 265-290.

desenvolvimento sustentável.

Além disso, analisando alguns países e também Estados que optaram pela tributação como mecanismo de defesa dos recursos naturais, pode-se constatar que inúmeros deles já realizaram, ou ainda estão a realizar uma espécie de reforma fiscal ecológica, ou seja, estão transformando os seus respectivos sistemas tributários para alterar as bases de arrecadação com a finalidade de se tributar condutas que tornam-se poluidoras.

A título de exemplo, o Estado do Rio de Janeiro anunciou uma medida pioneira no Brasil, que será a criação da Nota Verde com previsão de maiores descontos do IPVA para os carros novos menos poluentes. Também há previsão de maior controle para os carros antigos e que causem maior poluição, tal qual já ocorre em muitos países da Comunidade Europeia ${ }^{27}$.

Nesse prospecto, diante da averiguação da crise hídrica que o Brasil tem enfrentado, se faz necessário refletir quanto às intervenções em prol da natureza, bem como os respectivos resultados que possam ser alcançados através dos tributos. Além disso, relevante considerar também os aspectos quanto aos limites dos recursos naturais, de forma que sejam eles respeitados.

Nessa continuidade, considerando-se a estreita relação entre economia e o meio ambiente, surge a possibilidade de o Estado atuar por intermédio de instrumentos jurídicos, evitando e sancionando os degradadores ambientais, o que se pretende é justamente que as políticas públicas ambientais atuem como precaução, prevenindo, direcionando, controlando e estimulando atividades produtivas ambientalmente corretas e ordenadas. Assim sendo, uma política tributária ambiental mostrar-se-ia muito eficaz.

Convém ressaltar que a tributação ambiental não seria instrumento de punição da empresa cuja atividade é lícita à luz do comportamento jurídico. Todavia, admitindo-se que certas atividades produtivas causam impacto no meio ambiente, a tributação ecológica buscaria compor o custo socioambiental daquela atividade com a obtenção de receita precipuamente destinada a corrigir aquela agressão ambiental, e ao mesmo tempo em que induziria mudanças de comportamento não só pela determinação do Estado que proíbe, mas pela busca da atividade privada por uma solução mais econômica (reorientação da atividade empresarial) e, também, na reorientação na mudança de comportamento dos consumidores sem consciência das externalidades negativas.

${ }^{27}$ CAVALCANTE, Denise Lucena. Tributação Ecológica. Os reflexos da tributação ambiental sobre o meio ambiente e como fator de sustentabilidade. Artigo disponível em < http://sindifiscors.org.br/interna.php?secao_id=12\&campo=13559 > Acesso em: 06 de Junho de 2018. 
Artigo Original

Hegemonia - Revista Eletrônica do Programa de Mestrado em Direitos Humanos, Cidadania e Violência/Ciência Política do Centro Universitário Unieuro

ISSN: 1809-1261

UNIEURO, Brasília, número 27 (Especial), 2019, pp. 265-290.

Em que pese toda divergência doutrinária e questionamentos quanto ao tema, a tendência é um estreitamento cada vez maior do direito ambiental, seus princípios e instrumentos, com os demais ramos do direito, podendo-se até audaciosamente afirmar a convergência de direcionamento destes últimos em relação ao primeiro, inclusive com rompimento de diversos princípios e institutos até então tidos como absolutos, devido à necessidade de adequação da "sociedade moderna" aos limites da sustentabilidade, norteados pelo direito ambiental ${ }^{28 .}$

Ademais, a análise da possibilidade de um tributo ecológico deve passar pelo crivo de toda essência constitucional, notadamente do sistema tributário, observando seus princípios e regras. Todavia, deve-se prevalecer à razoabilidade, privilegiando as gerações futuras com o intuito de se obter condições mínimas ambientais para possibilitar o desenvolvimento sustentável.

O Brasil, embora possua uma Constituição muito analítica e limitadora em matéria de tributação, há alguns anos vem acumulando experiências na adoção de tributos visando fins ambientalmente desejados, podendo-se destacar a instituição de taxas, observando-se os fatos geradores que lhes são aplicáveis.

Não obstante, a crise hídrica enfrentada recentemente traz consigo grandes preocupações, o qual o Estado deve pensar em medidas cautelares e céleres para conter os efeitos danosos advindos dessa situação, seja ela através de implantação de novas políticas com o uso da tributação ou na retratação por negligenciar a preservação do recurso hídrico.

Dessa maneira, institui-se o tributo ambiental em razão de elementos primordiais que incorporam o fato gerador ligado a proteção do meio ambiente. Com isso, cumpre ressaltar que no sistema tributário brasileiro não há tributo com caráter estritamente ambiental, nem tão pouco a criação de novos tributos, porém trata-se de uma nova orientação de um determinado tributo já existente e previsto no ordenamento jurídico, mas com o foco voltado para a sustentabilidade.

O exemplo de tributação ambientalmente orientada mais considerável é o IPTU (imposto predial e territorial urbano) e o IPVA (imposto sobre propriedade de veículos automotores). O chamado IPTU Verde são benefícios fiscais assentidos à população, mediante a adoção dos princípios da sustentabilidade nas edificações. Já o IPVA verde é voltado à circulação de carros

\footnotetext{
${ }^{28}$ JACCOUD, Cristiane Vieira. Tributação Ambientalmente Orientada: Instrumento de Proteção ao Meio Ambiente. In: Congresso Nacional do CONPEDI - Conselho Nacional de Pesquisa e Pós-graduação em Direito, 15. Manuas, 2006.

$<$ http://www.publicadireito.com.br/conpedi/manaus/arquivos/anais/manaus/direito_tribut_cristiane_v_jaccound. pdf $>$. Acesso em: 18 de novembro de 2017.
} 
Artigo Original

Hegemonia - Revista Eletrônica do Programa de Mestrado em Direitos Humanos, Cidadania e Violência/Ciência Política do Centro Universitário Unieuro

ISSN: 1809-1261

UNIEURO, Brasília, número 27 (Especial), 2019, pp. 265-290.

mais eficientes no controle da emissão de gases.

Dessa forma, o que há é uma remodelação ecológica do sistema tributário nacional, que deve considerar o meio ambiente como uma diretriz necessária, inclusive, redirecionando ecologicamente os tributos que não tinham na sua origem tal preocupação ${ }^{29}$.

\section{2- CONCLUSÃO}

A Investigação teórica a que se propôs e demostrou o presente artigo, parte da averiguação da tributação com viés ambiental, haja vista que o Brasil está enfrentando uma crise hídrica, isto é, a ecologia também sofre limitações e atualmente quem está demonstrando a grandeza de seus limites é a água. Diante disso, cada vez mais a sociedade está sendo convocada a preservar, zelar, cuidar dos bens naturais para que estes se perpetuem por décadas.

Desta feita, é primordial a realização de novas diretrizes para a democracia ambiental, bem como uma tutela preventiva e cautelatória para que as riquezas naturais, as quais são sinônimos de vida, permaneçam às próximas gerações.

Sob essa perspectiva e considerando que a atual crise demanda diversas transformações tanto na produção como no consumo pautado na sustentabilidade, foram examinados os motivos para que o Estado, perante essa circunstância, assuma um papel de interventor com seus respectivos mecanismos para isso.

Nessa sequência, em uma segunda análise, observou-se também que em matéria tributária, o Estado pode interferir na economia em prol da proteção ambiental, e isso pode ocorrer por meio do aumento da carga tributária ou da diminuição dela.

Assim, para que o contribuinte adote uma conduta instituída na legislação, é concedido tratamento profícuo por meio de isenção, crédito presumido ou benefícios fiscais, o qual contempla uma vantagem com o fim de atrair vários contribuintes, induzindo-os a uma conduta ecológica. Destarte, quanto maior for esse incremento, maior será a possibilidade de se obter o previsto no ordenamento jurídico.

Desta forma, analisando o dito popular que: “O Brasileiro só aprender quando mexe no

${ }^{29}$ TIPKE, Klaus; LANG, Joachim. Direito tributário. Tradução de Luiz Dória Furquim. Título original: Steuerrecht. Porto Alegre: Sergio Antonio Fabris, 2008, p. 446. 
Artigo Original

Hegemonia - Revista Eletrônica do Programa de Mestrado em Direitos Humanos, Cidadania e Violência/Ciência Política do Centro Universitário Unieuro

ISSN: 1809-1261

UNIEURO, Brasília, número 27 (Especial), 2019, pp. 265-290.

bolso", a tributação poderá servir sim de mecanismo de disciplina à prática econômica impondo uma responsabilidade para com os bens ambientais. Dessa forma, a experiência é válida direcionando o Direito Tributário para relevância e urgência nas questões ambientais.

Nesse sentido, deve-se ponderar que, no caso de incentivos fiscais como instrumentos econômicos de promoção da defesa do meio ambiente, a repudiação de alguns contribuintes pelo estímulo fiscal, importa no pagamento de mais tributos, em contra partida quem optar pela não poluição pagará menos ou poderá ter isenção. Portanto, o incentivo torna-se mais adequado que a penalização, pois incitar se mostra mais eficaz quando aplicado da forma correta porque aqueles que se comprometerem com o zelo da natureza terão os incentivos fiscais sem a necessidade de vinculação de impostos, e com isso toda a coletividade terá um ganho.

\section{3 - REFERÊNCIAS BIBLIOGRAFICAS}

AMAZONAS, Maurício de Carvalho, Apud: BRANDÃO, Renata. Incentivo fiscal ambiental parâmetros e limites para sua instituição a luz da constituição federal de 88. Tese (Doutorado em Direito) - Programa de pós-graduação em Direito, Faculdade de Direito da Universidade de São Paulo, São Paulo, 2013. BRANDÃO, Renata. Incentivo fiscal ambiental parâmetros e limites para sua instituição a luz da constituição federal de 88. Tese (Doutorado em Direito) - Programa de pós-graduação em Direito, Faculdade de Direito da Universidade de São Paulo, São Paulo, 2013.

BECKER, Alfredo Augusto, Apud: NUNES, Cleucio Santos. Direito tributário e meio ambiente. São Paulo: Dialética, 2005.

BENJAMIN, Antonio Herman de Vasconcellos e. Meio ambiente e constituição: uma primeira abordagem. In: CONGRESSO INTERNACIONAL DE DIREITO AMBIENTAL, 6., 2002, São Paulo. Anais do 6. Congresso Internacional do Meio Ambiente: 10 anos da Eco-92: o direito e o desenvolvimento sustentável. São Paulo: IMESP, 2002. 840 p. Disponível em: <http://bdjur.stj.jus.br//dspace/handle/2011/8702>. Acesso em: 03 de novembro de 2017.

CORREIA Neto, Celso de Barros. O Avesso do Tributo: Incentivos e Renúncias Fiscais no Direito Brasileiro. $2^{\mathrm{a}}$ Ed. São Paulo: Almedina, 2016. P.92

CIRINO, Samia Moda; BASSOLI, Marlene Kempfer. Direito Tributário Ambiental: Benefícios Fiscais às Empresas para a Proteção do Direito Fundamental ao Meio Ambiente. V. 12, Londrina: Scientia Iuris, 2008.

Disponível

em: 
Artigo Original

Hegemonia - Revista Eletrônica do Programa de Mestrado em Direitos Humanos, Cidadania e Violência/Ciência Política do Centro Universitário Unieuro

ISSN: 1809-1261

UNIEURO, Brasília, número 27 (Especial), 2019, pp. 265-290.

<http://www.uel.br/revistas/uel/index.php/iuris/article/view/4168/3619>. Acesso em: 10 de novembro de 2017

CANOTILHO, José Joaquim; LEITE, José Rubens Morato (organizadores). Direito constitucional ambiental brasileiro. São Paulo: Saraiva, 2007.

CAVALCANTE, Denise Lucena. Tributação Ecológica. Os reflexos da tributação ambiental sobre o meio ambiente e como fator de sustentabilidade. Artigo disponível em < http://sindifiscors.org.br/interna.php?secao_id=12\&campo=13559 > Acesso em: 06 de Junho de 2018.

FREITAS, Juarez, Apud: RONCONI, Elizangela Pieta; POFFO, Gabriella Depiné. Sustentabilidade: O Caminho para as presentes e futuras gerações. In: DIREITO E SUSTENTABILIDADE. 1. [Recurso eletrônico on-line] organização CONPEDI/UFSC; coordenadores: Carlos André Hüning Birnfeld, Álvaro Gonçalves Antunes Andreucci, Luiz Ernani Bonesso de Araujo. Florianópolis: CONPEDI, 2014. Disponível em: <http://publicadireito.com.br/publicacao/ufsc/livro.php?gt=209>. Acesso em: 13 de outubro de 2017

FERREIRA FILHO, Manoel Gonçalves. Curso de Direito Constitucional. Ed. 38. São Paulo: Saraiva, 2012. P. 402

JACCOUD, Cristiane Vieira. Tributação Ambientalmente Orientada: Instrumento de Proteção ao Meio Ambiente. In: Congresso Nacional do CONPEDI - Conselho Nacional de Pesquisa e Pósgraduação em Direito, 15. Manuas, 2006.

<http://www.publicadireito.com.br/conpedi/manaus/arquivos/anais/manaus/direito_tribut_cr istiane_v_jaccound.pdf $>$. Acesso em: 18 de novembro de 2017

MOREIRA, Rafael Soares. Tributação Extrafiscal e Meio Ambiente: Rumo a Concepção de Tributo Ambiental. Monografia (Bacharel em Ciências Jurídicas e Sociais) - Graduação em Ciências Jurídicas e Sociais, Pontifícia Universidade Católica do Rio Grande do Sul, Rio Grande do Sul, 2011. P. 06 OLIVEIRA NETO, Alexandre. Compatibilidade de um tributo ambiental com o sistema tributário nacional. Dissertação (Mestrado em Direito) - Departamento de Direito Econômico, Financeiro e Tributário, Faculdade de Direito da Universidade de São Paulo - USP, São Paulo, 2014. P. 25 SORIANO, Kelly Schaper. A Defesa do meio ambiente na ordem econômica constitucional brasileira: $O$ direito por uma economia ecológica. Dissertação (Mestrado em Direito) - Centro de Ciências Jurídicas, Programa de Pós-Graduação em Direito, Universidade Federal de Santa Catarina, Florianópolis, 2014.

TIPKE, Klaus, Apud: NETTO DE OLIVEIRA, Alexandre. Compatibilidade de um tributo ambiental com o sistema tributário nacional. Dissertação (Mestrado em Direito) - Departamento de Direito 
Artigo Original

Hegemonia - Revista Eletrônica do Programa de Mestrado em Direitos Humanos, Cidadania e Violência/Ciência Política do Centro Universitário Unieuro

ISSN: 1809-1261

UNIEURO, Brasília, número 27 (Especial), 2019, pp. 265-290.

Econômico, Financeiro, e Tributário da Faculdade de Direito da Universidade de São Paulo - USP, São Paulo, 2014.

TIPKE, Klaus; LANG, Joachim. Direito tributário. Tradução de Luiz Dória Furquim. Título original: Steuerrecht. Porto Alegre: Sergio Antonio Fabris, 2008, p. 446.

TAVARES, André Ramos. Direito Constitucional Econômico. Ed. 3a. São Paulo: Método, 2011. P.187. SCHOUERI, Luís Eduardo. Normas Tributárias indutoras e intervenção econômica. Rio de Janeiro: Ed. Forense, 2005. P.12.

RONCONI, Elizangela Pieta; POFFO, Gabriella Depiné. Sustentabilidade: O Caminho para as presentes e futuras gerações. In: DIREITO E SUSTENTABILIDADE. 1. [Recurso eletrônico on-line] organização CONPEDI/UFSC; coordenadores: Carlos André Hüning Birnfeld, Álvaro Gonçalves Antunes Andreucci, Luiz Ernani Bonesso de Araujo. Florianópolis: CONPEDI, 2014. Disponível em: <http://publicadireito.com.br/publicacao/ufsc/livro.php?gt=209>. Acesso em: 13 de outubro de 2017. 